\title{
Control of Schistosomiasis and Soil- Transmitted Helminthiasis in Sub-Saharan Africa: Challenges and Prospects
}

\author{
Louis-Albert Tchuem Tchuenté \\ University of Yaoundé I, Laboratory of Parasitology and Ecology, \\ Centre for Schistosomiasis and Parasitology, Yaoundé
}

Cameroon

\section{Introduction}

Schistosomiasis and soil-transmitted helminthiasis (STH) are the most common types of parasitic infections in the world. These diseases have major health and socio-economic repercussions, and constitute an important public health problem in developing countries. Human schistosomiasis is caused by six species of schistosomes, i.e. Schistosoma haematobium, Schistosoma mansoni, Schistosoma japonicum, Schistosoma mekongi, Schistosoma intercalatum and Schistosoma guineensis; and is endemic in 78 countries, where 779 million people are at risk of infection. S. haematobium is responsible for urogenital schistosomiasis, and the other species cause intestinal schistosomiasis. It is estimated that 207 million people are infected (WHO, 2002; Steinmann et al. 2006). STH, also known as intestinal worm infection, is caused by four main species of worms commonly known as roundworms (Ascaris lumbricoides), whipworms (Trichuris trichiura) and hookworms (Ancylostoma duodenale and Necator americanus). It is estimated that STH affects more than 2 billion people worldwide, and the greatest numbers of infections occur in sub-Saharan Africa, the Americas, China and east Asia (WHO, 2006; Hotez et al., 2006; Brooker et al., 2006; Awasthi et al., 2003).

These diseases affect the poorest of the poor and infections are particularly abundant among people living in rural or deprived urban settings with low socio-economic status, lack of clean water and poor sanitation (Hotez et al., 2006). The morbidity caused by these worms is commonly associated with heavy infection intensities. Compared with any other age group, school-aged children and pre-school children are the most vulnerable group and they harbor the greatest numbers of intestinal worms. As a result, they experience growth stunting and diminished physical fitness as well as impaired memory and cognition (Crompton and Nesheim, 2002; Stephenson et al., 2000; Bethony et al., 2006). These adverse health consequences combine to impair childhood educational performance and reduce school attendance (Miguel \& Kremer, 2004; Hotez et al., 2008). Studies have demonstrated that children may acquire helminth infections early in life (Sousa-Figueiredo et al., 2008; Stothard et al., 2008); which causes initial organ damage that can remain subclinical for years and manifest overtly only later, in adulthood (WHO, 2006; Odogwu et al., 2006).

Despite the existence of tools in the 1970s and 1980s, control was sustained for a prolonged period only in few countries and almost no progress was made in sub-Saharan African 
countries, the most affected part of the world. In the 1990s, interest in the control of these diseases in Africa waned. Therefore, as with other neglected tropical diseases (NTDs), schistosomiasis and STH control has been overshadowed by other health priorities. The highest priority of the international health community was given to the 'big three', i.e. HIV/AIDS, tuberculosis and malaria, with less attention to other infections related to poverty (Molyneux et al., 2005).

Recent years have witnessed an increased interest in the control of NTDs, and today there exists a global momentum for the control of these diseases. The control of NTDs has become a priority on the agenda of many governments, donors and international agencies. The World Health Organization (WHO) has played a major role in this prospect. Indeed, under the aegis of WHO, all member states of WHO (over 200 countries) have endorsed in May 2001 the World Health Assembly resolution WHA 54.19, with as a major objective the regular treatment of at least $75 \%$ of all school-aged children at risk of morbidity by 2010 . The renewed impetus for schistosomiasis and STH control has generated a greater political commitment, as well as an unprecedented opportunity for cost-effective action (Molyneux et al., 2005). This momentum has encouraged many countries to establish national action plans and programmes to control schistosomiasis, STHs and other NTDs (Hotez et al., 2009; Tchuem Tchuenté \& N'Goran, 2009). Within the past decade, significant progress has been made on large scale treatments through integrated control of schistosomiasis, STH and other NTDs, thanks to a number of international organizations, donor foundations, bilateral institutions and non-governmental organizations that responded to the $2001 \mathrm{WHO}$ 's call for action (Savioli et al., 2009). Today, treatment is cost-effective and the 'preventive chemotherapy' is currently the strategy of choice (WHO, 2006). With a support from the American (USAID) and British (DFID) governments, as well as the Bill and Melinda Gates Foundation, the pharmaceutical industry, and many not-for profit organizations, millions of children are regularly treated for schistosomiasis, STH and other NTDs. However, the control of these diseases is a long-term undertaking which involves several challenges. This paper highlights the progress made and also focuses on some main challenges that are reviewed and discussed.

\section{Epidemiology and burden of schistosomiasis and STH}

Schistosomiasis and STH transmission are intimately associated with poverty and poor sanitation. For schistosomiasis, infecion is caused by penetration of the skin by larvae in water; whereas for STH, infection is caused by the ingestion of parasite eggs from contaminated food or dirty hands - in the case of A. lumbricoides and T. trichiura - or by active penetration of the skin by larvae in the soil - in the case of hookworms. People who get infected carry parasite eggs in the feces or in the urine (in the case of urinary schistosomiasis), and in areas where there is no latrine systems the soil and water around the villages and communities are contaminated with feces or urine containing worm eggs. Although schistosomiasis and STH infections occur predominantly in rural areas, the social and environmental conditions in many unplanned slums and squatter settlements of developing countries are ideal for their persistence (Crompton \& Savioli, 1993). In endemic populations, infections are aggregated: most infected individuals in a community will have infections of a light or moderate intensity, while a few will be heavily infected. Heavily infected individuals suffer most of the clinical consequences of the infections and are the major source of infection for the rest of the community (WHO, 2002). 
The epidemiology of helminth infections is influenced by several key determinants, including environment, population heterogeneity, age, household clustering, genetics and polyparasitism (Hotez et al., 2008). In recent years, considerable progress has been made in the use of geographical information system (GIS) and remote sensing (RS) to better understand helminth ecology and epidemiology, and to develop low-cost ways to identify target populations for treatment. GIS and RS were used to describe the global distribution of schistosomiasis and STH infections and to estimate the number of infections in school-age children in sub-Saharan Africa.

There is considerable geographical variation in the occurrence of infections (Brooker et al., 2009). In general, changes with age in the average intensity of helminth infections tend to be convex, rising in childhood and declining in adulthood. For schistosomiasis, A. lumbicoides and T. trichiura, the heaviest and most frequent infections are in children aged 5-15 years, with a decline in intensity and frequency in adulthood (Gilles, 1996). In contrast, hookworm frequently exhibits a steady rise of intensity of infection with age, peaking in adulthood (Bethony et al., 2002). Household clustering of infected individuals has been demonstrated for STH (Forrester et al., 1988), and this can persist through time, as shown by familial predisposition to heavy infection with A. lumbricoides and T. trichiura (Forrester et al., 1990). Because morbidity is associated with worm burden rather than the absence or presence of infection, prevalence is commonly combined with worm burden (intensity of infection) to assess the epidemiological situation for schistosomiasis and STH infections. Worm burden is commonly measured by the number of eggs per gram (EPG) of feces or eggs per $10 \mathrm{ml}$ of urine (Anderson, 1982; Montresor et al., 1998). Prevalence and intensity of infections are used to classify communities into transmission categories, which enable to determine the appropriate type of mass treatment a community should receive (WHO, 2006). Both should be assessed in monitoring the impact of deworming campaigns.

\section{Control of schistosomiasis and STH}

\subsection{Progress towards the 2010 global target}

Progress in implementing schistosomiasis and STH control programmes has been slow but steady. Since 2006, there has been an overall increase in the number of people treated for schistosomiasis and STH. The increase in treatments has occurred entirely in the African Region, where the number of people treated more than doubled from 2006 to 2009 (WHO, 2011). This number increased by $93 \%$ in 2010 . The increase in the number treated suggests that both governments and their donor partners are now investing in schistosomiasis control (WHO, 2012). In 2010, 18 over 42 schistosomiasis endemic countries in the African region and 34/46 STH endemic countries or territories reported their treatment data to WHO. Overall, 27,983,327 people were treated for schistosomiasis, and 91,025,863 children for STH (Table 1).

\begin{tabular}{lcc}
\hline Characteristics & Schistosomiasis & STH \\
\hline No. endemic countries & 42 & 46 \\
No. countries reporting MDA data & 18 & 34 \\
No. people requiring treatment & 220578484 & 283800000 \\
No. people treated & 27983327 & 91025863 \\
No. pre-school aged children treated & - & 42711551 \\
No. school aged children treated & - & 48314312 \\
\hline
\end{tabular}

Table 1. African Regional summary of children treated for schistosomiasis and STH, 2010 
Figure 1 illustrates the progress in Africa ten years after the 2001 WHA resolution. Although significant progress has been made over the past years to significantly reduce schistosomiasis and STH infection prevalence below low risk, or to regularly implement mass drug administration (MDA) in several countries, the global achievement is still very far from the WHO's target of regular deworming of at least $75 \%$ of school-age children at risk. Indeed, from the data of epidemiological coverage of STHs, it was estimated that only $15 \%$ of school-aged children at risk of infection have been treated with preventive chemotherapy in 2008 (WHO, 2010). School-based deworming interventions still cover only a minority of children considered to be at risk despite the low cost of these interventions and their significant impact on health. More worrying, the number of people treated for schistosomiasis in Sub-Saharan Africa is estimated to be only $6.71 \%$ of the people infected (WHO, 2011). The major constraint to controlling schistosomiasis continues to be the limited access to praziquantel (Hotez et al., 2010). In the African Region, only few countries (18 in 2008) have achieved the $75 \%$ treatment target.

\subsection{Taking advantage of integrated control of NTDs}

In the developing world, polyparasitism is the norm rather than the exception (Molyneux et al., 2005; Fleming et al., 2006; Tchuem Tchuente et al., 2003). In large parts of the world, particularly in Africa, most children are infected by more than one species of helminth. These NTDs frequently overlap geographically and they impose a great burden on poor populations, affecting the same individuals. Therefore, the current strategy for NTD control is to integrate interventions for multiple diseases (Molyneux et al., 2005). This integrated approach is the basis for cost-effectiveness and streamlined efficiency. Also, because many of the drugs used for mass treatment are provided free of charge by major multinational pharmaceutical companies, the MDA approach is the most cost-effective global public health control measure (Hotez et al., 2007). Schistosomiasis and STH infections are the most prevalent and widespread of the common NTDs, and they overlap in many parts with many of the other NTDs. Therefore, an integration of schistosomiasis and STH control with other helminth control programmes and a good coordinated use of (donated) drugs would be highly beneficial for their control. This would indeed allow to take advantage of drug donation and co-administration, and to optimize the preventive chemotherapy.

Within the past decade, significant progress has been made on large-scale treatment of schistosomiasis and STH through integrated control with other NTDs, thanks to a number of international organizations, donor foundations, bilateral institutions and nongovernmental organizations that responded to the 2001 WHO's call for action (Savioli et al., 2009). With a support from the American (USAID) and British (DFID) governments, as well as the Bill and Melinda Gates Foundation, the pharmaceutical industry, and many not-for profit organizations, millions of children are regularly treated for schistosomiasis, STH and other NTDs. Today, an integrated control of NTD using the preventive chemotherapy is operating in more than 15 countries. Within the first three years (2006-2009) of implementation of the USAID NTD Control Program, the number of persons reached each year increased progressively, with a cumulative total of 98 million persons receiving 222 million treatments (Linehan et al., 2011). In West Africa, nearly 13.5 million doses of albendazole have been administered against STH between 2004 and 2006 in Burkina Faso, Mali and Niger, with coverage rates varying between $67.0 \%$ and $93.9 \%$ (Garba et al., 2009). Monitoring and evaluation activities after large-scale administration of praziquantel for schistosomiasis and albendazole for STH showed a significant decrease in the intensity of infections. Also, there was a significant increase in haemoglobin concentration after 1 and 2 


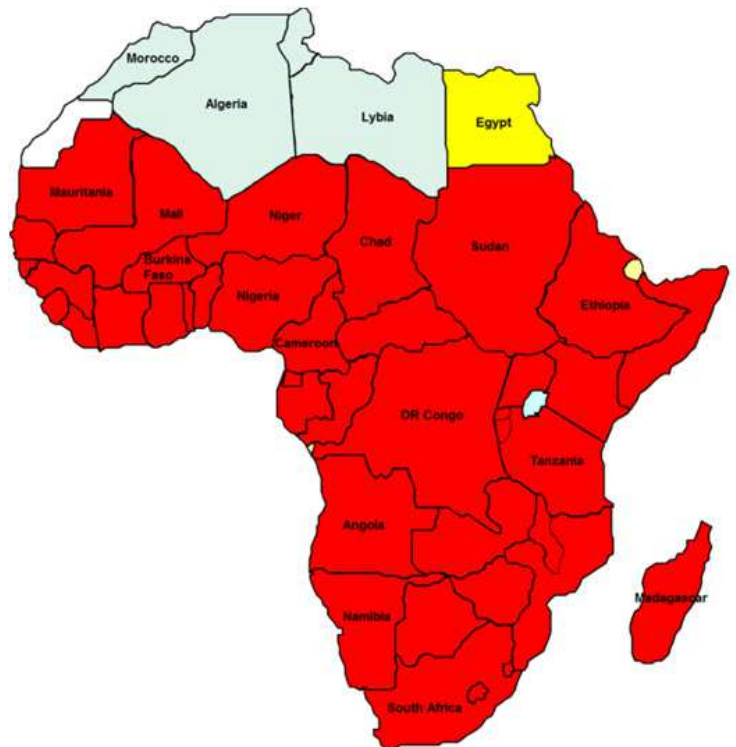

(A)

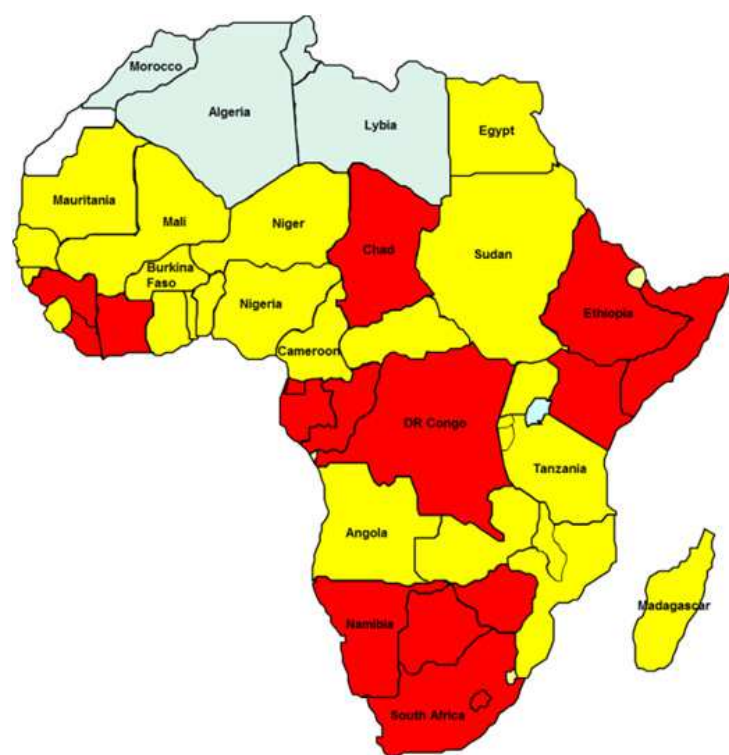

(B)

Countries likely to have achieved interruption of transmission or towards elimination

Countries with on-going large-scale schistosomiasis control programme

Countries with limited or no schistosomiasis control programme

Fig. 1. Comparative status of schistosomiasis control in Africa at the end of the 20th century (A) and in 2010 (B). 
years of treatment (Fenwick et al., 2009). Combination of ivermectin and albendazole, and co-administration of praziquantel and albendazole or mebendazole have been proven to be safe, with no side effects outside those commonly associated with each of these drugs (Horton et al., 2000; Olds et al., 1999). Though WHO does not formally recommends combination of praziquantel and ivermectin yet, recent studies have demonstrated the safety of triple co-administration of praziquantel, albendazole and ivermectin in areas where schistosomiasis, STH and LF or/and onchocerciasis are co-endemic and where several rounds of treatment with one or two drugs have been implemented in the past (Mohammed et al., 2008).

\subsection{A country example: Cameroon}

In Cameroon, schistosomiasis and STH are important parasitic diseases. Recent estimates indicate that at least 2 million people are infected with schistosomiasis, 5 million are at risk and more than 10 million are infected with gastrointestinal helminths (Minsante, 2005). In 1983, a pilot project for schistosomiasis control, funded by USAID, was set up. Within this framework a national epidemiological survey of schistosomiasis and STH was conducted between 1985 and 1987. Overall, 49 divisions, 504 schools and 23850 schoolchildren were investigated. The results showed the occurrence of S. haematobium, S. mansoni, S. guineensis, A. lumbricoides, $T$. trichiura and $N$. americanus as the major helminth species. The highest transmission levels of schistosomiasis occured in the northern part, whereas STH were more prevalent in the southern part of the country (Ratard et al., 1990, 1991; Brooker et al., 2000). When considering all these helminthic diseases, no region of the country is spared. However, this pilot project stopped in 1989 when the USAID support ended.

Taking advantage of the renewed momentum for NTDs, the national programme for the control of schistosomiasis and STH was created in March 2003. There is a strong political commitment from the Ministries of Public Health and Basic Education. These two ministries work in close collaboration and this inter-sectorial engagement is consolidated by the fact that the national steering committee for the control is co-chaired by the Minister of Public Health and the Minister of Basic Education, as president and vice-president, respectively. The Cameroonian proposal for support to SCI was presented by the Minister of Public Health himself who attended the SCI advocacy meeting in London in July 2003. Therefore, the non-selection of Cameroon for SCI support came both as a surprise and a disappointment. Beyond the main ranking criteria, including the existence of a strategic plan for control, the strong political commitment and the quality of the proposal, the SCI selection was finally made on a regional combination of three East African countries and three West African countries, with emphasis on country-regional collaboration and consortium. In spite of this, the Cameroonian government made necessary efforts to ensure the success of the schistosomiasis and STH control, as it was among the priority programmes of the country. Hence, the national control programme was officially launched on 25 March 2004.

The action of the programme during the past few years was intense and multifaceted, with a number of key achievements. Based on the limited resources available, the priority activities were centred on three major activities: (1) the production of various strategic documents necessary for the implementation of the activities and advocacy; (2) the advocacy and the mobilisation of partners and funding; and (3) the implementation of activities in selected areas. A strong emphasis was put on advocacy, the results of which were encouraging for future activities and plans. The most important was the selection of Cameroon as the first 
start-up country for mebendazole donation in Africa. Indeed, in 2005 Johnson \& Johnson established a partnership with the Task Force for Child Survival and Development (currently The Task Force for Global Health) to develop a programme to donate mebendazole via a multi-disciplinary initiative designed to address intestinal worm infections in the most at-risk children of the world. Cameroon was selected as the start-up country for this drug donation programme because of its leadership and commitment to eliminating infections as a major public health problem (http://www.janssenpharmaceutica.be/download_Cameroen_N.asp). With regard to control, a pilot phase was completed in February 2006 in one health district, where approximately 20,000 school-aged children were treated with praziquantel and albendazole. Subsequently, the activities were extended to one entire region of the ten regions in Cameroon, i.e. the Adamawa region in the northern part of the country. This was implemented with support from partners, including the World Food Programme (WFP), the Canadian Co-operation, the United Nations International Children's Emergency Fund (UNICEF) and SCI/Medpharm (which donated the drugs praziquantel and albendazole). Deworming was conducted in all 500 primary schools in this region, and approximately 150,000 school-aged children were treated in May 2006. Overall, 700 head teachers, 500 representatives of parent teacher associations, and 2500 teachers were trained. In addition, parasitological surveys for schistosomiasis and STH were conducted in 40 selected schools where stool and urine samples were collected from a total of 1830 children.

The mebendazole donation enabled the national control programme to scale-up activities rapidly. As a result, deworming activities were increased to encompass all ten regions. In 2007, Cameroon launched a nationwide deworming campaign, and 4 million school-aged children were treated. The launching ceremony allowed the government and partners to further reaffirm their commitment and to galvanise communities, international development agencies, non-governmental organisations (NGOs) and other stakeholders to join in the effort to implement fundamental improvements in disease control and prevention. The country has in place school-based and community-directed channels and in the programme teachers and community drug distributors administer the drugs to children along with health and hygiene education. The major activities conducted are: (1) training of health and education personnel, (2) sensitization and education of communities about the disease, the risks of infection and measures for prevention, (3) promotion of hygiene, safe water and sanitation systems in communities, and (4) deworming of children. Since 2007, 4 million school-age children are treated annually with mebendazole, with the involvement of over 75,000 trained teachers and head teachers. Control of STH is primarily implemented through school-based distribution of mebendazole, co-administered with praziquantel where schistosomiasis is endemic. In addition, albendazole is co-administered with ivermectin during the community-directed treatment for LF. Furthermore, over 2.7 million children aged 1-5 years are dewormed during child health week campaigns implemented twice a year (Tchuem Tchuenté and N'Goran, 2009).

Moreover, parasitological surveys were conducted in selected schools in all 63 health districts of the Centre, East and West regions of Cameroon, in order to update the disease distribution map, to assess the impact of previous deworming campaigns, and to determine where treatment with PZQ should be extended. The results showed significant variation of schistosomiasis and STH prevalence between schools, villages, districts and regions. In comparison to previous mapping data collected 25 years ago, the results showed an increase of schistosomiasis transmission in several health districts, where PZQ MDA was not implemented so far. On the contrary, there was a significant decline of STH infection 
prevalence and intensities in all three regions, with an overall decline of prevalence from 90.06\% (95\% CI: $89.45-90.63 \%$ ) to $24.11 \%$ (95\% CI: $23.37-24.86 \%$ ). Based on the prevalence data, the continuation of annual or bi-annual MDA for STH was recommended, as well as an extension of PZQ treatment in identified moderate and high risk communities for schistosomiasis (Tchuem Tchuenté et al., 2012). These results show the positive impact of annual deworming campaigns, and illustrate the progressive success of the national programme for the control of schistosomiasis and STH in Cameroon. This is illustrated in Figure 2. Parasitological surveys are in progress in the remaining regions of Cameroon for the update mapping.

\section{Challenges}

The control of schistosomiasis and STHs is a long-term undertaking, which involves several challenges. The first challenge is to mobilize the funds required for successful actions. Unlike some of the stigmatising NTDs with 'visible' morbidity such as onchocerciasis and LF which have successfully raised funding for the implementation of control activities, little funding are globally available for the implementation of schistosomiasis and STH control alone. Therefore, for their schistosomiasis and STH control programmes, endemic countries should take advantage of the opportunities resulting from the global growing financial resources generated by the new partnerships and impetus for NTD control. The recent changes in the international agenda and the increasing funding opportunities provide leverage for the control of schistosomiasis and STHs. The piggyback and integrated control approaches - based on a complementary co-administration of relevant drugs - are the basis for cost-effectiveness and streamlined efficiency. However, pigging back on other interventions or integration with other health programmes requires the setting up of clear efficient coordination mechanisms in order to optimize the use of resources mobilized from various partners. Among other challenges, the most important are the co-ordination at various levels, the country ownership and leadership, the scale up of control, the sustainability of control programmes, the strengthening of partnerships and institutional capacities, the implementation of operational research, monitoring and evaluation, and the development of new diagnostic tools.

\subsection{Co-ordination}

The NTD control programmes involve many partners and stakeholders, different diseases, several funding sources, and multiform resources. The main challenge is to set up clear efficient coordination mechanisms in order to optimize the resources mobilised from all partners. To ensure transparency in all processes, there is a need for a coordination mechanism for funding, drug supplies and integrated control of NTDs to enable all stakeholders to share information. The coordination mechanism should be at global, regional and country levels. The precise form of this co-ordination mechanism needs to be explored and agreed amongst stakeholders. At national level, the Ministry of Health should play the central role in this co-ordination.

\subsection{Country ownership and leadership}

In order to ensure the sustainability and the success of NTD control programmes, country leadership in the coordination of activities is essential. Each partner may have its own vision and own interest, and the ones who bring the money also sometimes decide what to do. 


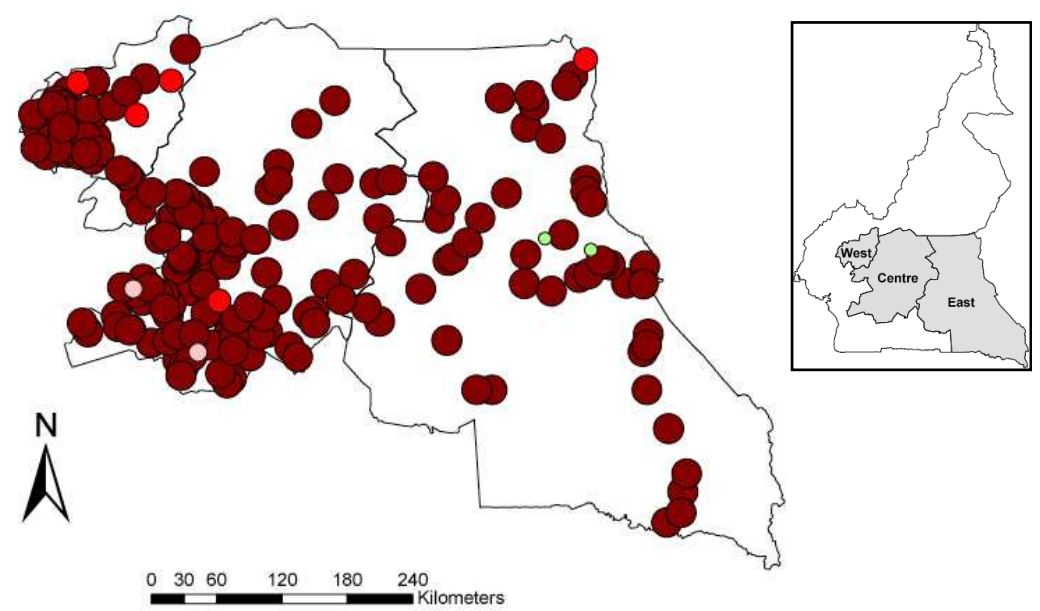

(A)

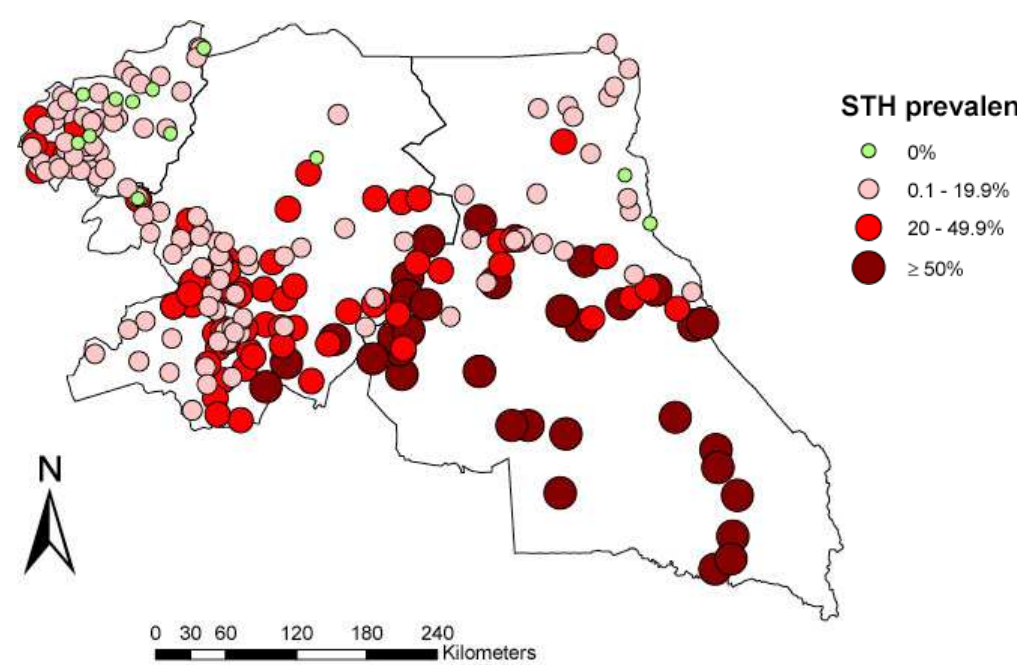

(B)

Fig. 2. Comparative maps of the overall soil-transmitted helminthiasis prevalence between the years 1985-1987 (A) and 2010 (B) in the Centre, East and West regions of Cameroon.

Sometimes, many people in a country are working for the same thing, but with different targets because there are different donors. Country ownership brings many gains, including development of local capacity and expertise. There should be a strong political commitment to tackle NTDs in endemic countries. Indeed, examples of success stories are from those countries (e.g. Japan, Morocco and China) that had clear ambitious goal, with high government and national commitment, funding mobilization and leadership. For example, in early 1963 STH occurred in Okinawa, Japan at high prevalence up to $40 \%$ in adult population. Through the development of an ambitious 'zero parasites' campaign a successful control was conducted and within a period less than 10 years STHs and other 
parasites were eradicated in Okinawa. In contrary, lack of ambitious control is remarkable in Sub-Saharan Africa where many countries have passive attitude, waiting for partners to decide and to tell them what to do. African governments should develop more positive and ambitious approach for the control of NTDs, and donors and agencies beyond disease endemic countries - the agents of aid to developing countries-will need to accept that countries must have ownership of their health systems and total control over decisions about the health of their people.

\subsection{Scale up of control}

In order reach the target set by WHA for the different NTDs, there is a need to accelerate the extent of treatment. The extension of regular deworming coverage as a public health intervention to reach all individuals at risk remains a challenge. There is also a challenge to tackle the big countries such as Nigeria, Democratic Republic of Congo, Ethiopia and Tanzania which count for $60 \%$ of at risk population not covered by preventive chemotherapy yet. In the context of multi-disease integrated control, the current tendency in sub-Saharan Africa is to integrate helminth control within the community-directed interventions, taking advantages of the long experience and gains of onchocerciasis and LF control programmes through the establishment of community-directed treatment with ivermectin (CDTI) in all countries supported by the African Programme for Onchocerciasis Control - APOC (Sékétéli et al., 2002; Amazigo et al., 2002). Yet, in the majority of countries, STHs are more widely distributed than both onchocerciasis and LF. Therefore, the challenge will be to extend MDA coverage in those areas where CDTI does not exist. Countries should thus act cautiously and anticipate to avoid to neglect STH and schistosomiasis control in those endemic areas. School-based deworming is probably the simple, cost-effective and best sustainable way to expand coverage of children. With more schools than clinics, and more teachers than health workers, the existing and extensive education infrastructure provides the most efficient way to reach the highest number of school-age children and to reach the WHO target of covering at least $75 \%$ of all school-aged children in need. The recent increases of donated anthelminthic medicines by Merck KGaA (praziquantel), Johnson \& Johnson (mebendazole) and GlaxoSmithKline (albendazole) constitute a real boost towards the achievement of this goal.

\subsection{Sustainability}

To roll back the NTDs, it is necessary to continue and maintain the implementation of control activities during very long period. The programme should be long-term, and financial and implementation plans should be made accordingly. This would avoid one of the major errors of the past where most of the programmes were supported by short-term external funds and stopped immediately when funds ceased. To ensure sustainability, countries should, from the beginning, envisage strategies to: (1) keep the momentum, interest and enthusiasm for the control of the diseases; (2) organize and finance in a sustained way the distribution of drugs to those who need them; (3) mobilize funding for operational costs for drug distribution, health education materials, baseline data collection, monitoring and evaluation, etc.; (4) ensure the availability and affordability of the drugs at community level in endemic areas; (5) integrate programme activities within the existing health structures and networks; and (6) strengthen the health system and national capacity at all levels, especially in the peripheral and remote areas which manage the greater number of communities and infected persons. One of the key questions is how to guarantee the continuation of control after the decline or interruption of external funds. 


\subsection{Strengthening of partnership}

An efficient control requires multisector collaboration and multilateral funding. No single organization can hope to achieve this goal alone. School-aged children are the target group for schistosomiasis and STH, so the collaboration between the Ministry of Health and the Ministry of Education should be reinforced. The target group for the different filarial infections is the entire population and the control strategy is based on community-directed interventions, which requires ownership by the communities and strong partnership with NGOs. Overall, partnership with other government departments and NGOs concerned with water supply, sanitation and development projects should be developed and reinforced.

\subsection{Strengthening of institutional capacities}

The integration of control activities within the health services is fundamental for the sustainability of the programme. However, most of the existing structures do not have the capacity to ensure the implementation of these activities, leading to programme failure. Therefore, the strengthening of the health system is a requirement for the long-term viability of the control programme. Furthermore, an efficient participation of schools and communities in the disease control requires a reinforcement of capacity of the school system and the community ownership.

\subsection{Operational research}

It is important to support operational research to fulfill gaps and improve the implementations of the control. For example, the understanding of some key issues, such as baseline epidemiology, morbidity assessment, drug efficacy testing and monitoring of drug resistance, is of vital importance.

\subsection{Monitoring and evaluation}

Regular monitoring and evaluation are necessary to ensure that programmes are efficiently implemented and that the beneficiaries gain the maximum benefit. This is particularly challenging given the diversity of tools and indicators. Substantial progress has been made towards the development of standardized tools for monitoring and evaluating NTD control programmes. WHO is currently developing guidelines based on the experience to date with integrated preventive chemotherapy interventions.

\subsection{Better diagnostic tools}

Because of its simplicity and relatively low-cost, the Kato-Katz technique (Katz et al., 1972) is widely used for epidemiological field surveys and is recommended by the WHO for surveillance and monitoring of schistosomiasis and STH control programmes (WHO, 1991; Montresor et al., 1998). Though the specificity is very high, the sensitivity of Kato-Katz in single stool sample examination is limited by day-to-day variation in egg excretion leading to measurement error in estimating the presence of infection. This is particularly accentuated in areas with high proportions of light intensity infections (Hall, 1981; Booth et al., 2003; Tarafder et al., 2009). In the current era of preventive chemotherapy, the intensification of large-scale interventions and repeated mass deworming will significantly reduce the prevalence and intensities of schistosomiasis and STH infections (Savioli et al., 2004; Kabatereine et al., 2007). As consequence of the increase of low-intensity infections, more light infections will be often missed if single stool samples are examined by Kato-Katz method, resulting in high underestimation rates. Therefore, there is a need to develop and 
validate more sensitive diagnostic tools for accurate surveillance and monitoring of schistosomiasis and STH control programmes, and for monitoring of drug efficacy. Some studies recommended multiple stool samples in order to avoid underestimating the 'true' prevalence and transmission potential of schistosomiasis and STH infections. Indeed, it was demonstrated that Kato-Katz examination of 3 instead of 1 stool specimen increased the sensitivity of helminth diagnosis, most notably for hookworm (Steinmann et al., 2008; Knopp et al., 2008) and intestinal schistosomiasis (De Vlas and Gryseels, 1992; Lin et al., 2008). Recent studies suggested that urine circulating cathodic antigen (CCA) assays maybe an appropriate test for the diagnosis of $S$. mansoni in moderate transmission zones (Shane et al., 2011; Stothard et al., 2011; Tchuem Tchuenté et al., 2012). Several alternative stool examination techniques have been tested for the detection of STH infections. FLOTAC, a new technique mainly used in the veterinary field, was suggested as a suitable diagnostic tool particularly in situations of low parasite infection intensities (Cringoli, 2006). Recent studies found that a single FLOTAC examination was more sensitive than triplicate KatoKatz thick smears for the diagnosis of low-intensity STH infections (Knopp et al., 2009). In particular, the FLOTAC technique improves the ability to diagnose human hookworm infections accurately (Utzinger et al., 2008), which is generally underestimated when using Kato-Katz thick smears due to a rapid disintegration of hookworm eggs and the constraint to read the slides very shortly (within $30 \mathrm{~min}$ ) after preparation (Dacombe et al., 2007). FLOTAC was thus suggested as a suitable method for a rigorous surveillance of helminth control programmes, monitoring of STH transmission and verification of local elimination (Knopp et al., 2009). McMaster, another flotation technique commonly used in veterinary parasitology, is an alternative diagnostic tool. The results of a comparative study of four techniques, i.e. ether-based concentration, Parasep Solvent Free, McMaster and FLOTAC, showed that despite the fact that McMaster was less sensitive than FLOTAC, the former technique was the most feasible and easy to perform under field conditions. McMaster appeared as a promising technique of choice when using fecal egg counts for monitoring of drug efficacy against STHs (Levecke et al., 2009). Overall, several techniques are available for the detection of STH infections, with significant difference in the cost, sensitivity, simplicity and field applicability. Though a true 'gold standard' test with $100 \%$ accuracy does not exist, Kato-Katz thick smears is so far commonly and widely used as the basic and 'default' technique for helminth epidemiology, despite some limitations.

Further efforts should be made to validate other detection tools (Tchuem Tchuenté, 2011). The choice of a specific diagnostic assay should be governed by the objective of the activity, and according to the stage of helminth control (Berquist et al., 2009). As the accuracy of a given diagnostic technique may vary significantly according to helminth transmission level, tools should be adapted when moving from morbidity control to elimination of infection. Moving toward the surveillance and elimination phases requires more sensitive techniques such as antibody detection. However, sero-diagnostic tools for detection of helminth infections require blood sample collection (invasive), access to affordable, high-quality reagents; which are important limiting factors for their integration into large-scale national control programmes. These are probably some of the reasons why today only a few countries have adopted antibody detection as a key strategy in helminth diagnosis (Berquist et al., 2009).

\subsection{New paradigm shift: Moving from control to elimination}

In the past years, the costs of PZQ and the lack of resources were major constraints for the control of schistosomiasis. Today, there exists new impetus for the control, with increasing funding opportunity and donated PZQ by pharmaceutical companies. Therefore, there is an 
opportuny to take up the challenge, to be more ambitious and to move from control to elimination where feasible. To do this there is a need to adapt the current threshold for intervention (i.e. prevalence $>10 \%$ ) and to carefully define the implementation unit for PZQ mass administration. Treatment algorithms should be re-defined based on current knowledge and experiences.

\section{Conclusion}

During the past several decades, many attempts have been made to control schistosomiasis, STH and other NTDs. Important advances have been made such as the development of praziquantel, albendazole and mebendazole, the current drugs of choice for these NTDs, which amplified treatment possibilities to the majority of people who need it. Although few control successes were achieved, the global objective is long way off and these diseases remain important public health problems in developing countries. Fulfilling the mandate of the World Health Assembly resolution 54.19 will require the regular treatment of hundreds of millions of children over decades. A successful control of schistosomiasis and STHs across the endemic regions calls for strengthening health system and interventions, ensuring access to anthelminthic drugs in all health services, co-implementation and the coordinated use of the different anthelminthic drugs, promotion of access to safe water, adequate sanitation and health education, and mobilization of resources to sustain control activities. The challenge also includes an improvement of drug efficacy for a much better rapid impact. Indeed, the low cure rate of the recommended drugs for STH, at the single dose as commonly used, highlights the need for an alternative strategy based either on a multipledays treatment regimen, an alternating use of albendazole and mebendazole from one deworming round to another, or the use of an alternative drug. A multiple day treatment would obviously increase the costs, but the immediate and long-term benefits would be priceless. Today, there exist new impetus to global helminth control and a series of favourable factors for implementing successful control programmes. There are several and increasing funding opportunities, and we have a great opportunity to properly take up the challenge and relieve poor communities from disease burden that jeopardise their development. There is an urgent need for well co-ordinated and transparent use of multisource funds to increase efficiency and to avoid duplication of efforts. We should act cautiously and address the dilemma between costs and efficacy of interventions, and between control and elimination. Time is right to act more ambitiously and to set the agenda for schistosmiasis and STH elimination.

\section{Acknowledgements}

The author gratefully acknowledges all partners and stakeholders who contribute towards the successful control of schistosomiasis and STH in Cameroon.

\section{References}

Amazigo, U.V., Obono, O.M., Dadzie, K.Y., Remme, J., Jiya, J., Ndyomugyenyi, R., Roungou, J.B., Noma, M., Sékétéli, A. (2002). Monitoring community-directed treatment programmes for sustainability: lessons from the African Programme for Onchocerciasis Control (APOC). Ann. Trop. Med. Parasitol. 96 (Suppl. 1), S75-S92. 
Anderson, R.M. (1982). Population Dynamics of Infectious Diseases: Theory and Applications. Chapman and Hall, London, United Kingdom, 377 pp.

Awasthi, S., Bundy, D.A., Savioli, L. (2003). Helminth infections. British Medical Journal 327, 431-433.

Berquist, R., Johansen, M.V., Utzinger, J. (2009). Diagnostic dilemmas in helminthology: what tools to use and when? Trends Parasitol. 25, 151-156.

Bethony, J., Brooker, S., Albonico, M., Geiger, S.M., Loukas, A., Diemert, D., Hotez, P.J. (2006). Soil-transmitted helminth infections: ascariasis, trichuriasis, and hookworm. Lancet 367, 1521-1532.

Bethony, J., Chen, J., Lin, S., Xiao, S., Zhan, B., Li, S., Xue, H., Xing, F., Humphries, D., Yan, W., Chen, G., Foster, V., Hawdon, J.M., Hotez, P.J. (2002). Emerging patterns of hookworm infection: influence of aging on the intensity of Necator infection in Hainan Province, People's Republic of China. Clin. Infect. Dis. 35, 1336-1344.

Booth, M., Vounatsou, P., N'Goran, E.K., Tanner, M., Utzinger, J. (2003). The influence of sampling effort and the performance of the Kato-Katz technique in diagnosing Schistosoma mansoni and hookworm co-infections in rural Côte d'Ivoire. Parasitology 127, 525-531.

Brooker, S., Clements, A.C.A., Bundy, D.A.P. (2006). Global epidemiology, ecology and control of soil-transmitted helminth infections. Advance in Parasitology 62, 221-261.

Brooker, S., Donnelly, C.A. and Guyatt, H.L. (2000). Estimating the number of helminthic infections in the Republic of Cameroon from data on infection prevalence in schoolchildren. Bulletin of the World Health Organization 78, 1456-1465.

Brooker, S., Kabatereine, N.B., Smith, J.L., Mupfasoni, D., Mwanje, M.T., Ndayishimiye, O., Lwambo, N.J.S., Mbotha, D., Karanja, P., Mwandawiro, C., Muchiri, E., Clements, A.C.A., Bundy, D.A.P., Snow, R.W. (2009). An updated of human helminth infections: the example of East Africa. Int. J. Health Geogr. 8, 42.

Cringoli, G. (2006). FLOTAC, a novel apparatus for a multivalent faecal egg count technique. Parasitologia 48, 381-384.

Crompton, D.W., Savioli, L. (1993). Intestinal Parasitic Infections and Urbanization. Bull. World Health Organ. 71, 1-7.

Crompton, D.W.T., Nesheim, M.C. (2002). Nutritional impact of intestinal helminthiasis during the human life cycle. Ann. Rev. Nutr. 22, 35-59.

Dacombe, R.J., Crampin, A.C., Floyd, S., Randall, A., Ndhlovu, R., Bickle, Q., Fine, P.E.M. (2007). Time delays between patient and laboratory selectively affect accuracy of helminth diagnosis. Trans. R. Soc. Trop. Med. Hyg. 101, 140-145.

De Vlas S.J., Gryseels B. (1992). Underestimation of Schistosoma mansoni prevalences. Parasitology Today 8: 274-277.

Fenwick, A., Webster, J.P., Bosque-Oliva, E., Blair, L., Fleming, F.M., Zhang, Y., Garba, A., Stothard, J.R., Gabrielli, A.F., Clements, A.C.A., Kabatereine, N.B., Toure, S., Denbele, R., Nyandindi, U., Mwansa, J., Koukounari, A. (2009). The Schistosomiasis Control Initiative (SCI): rationale, development and implementation from 20022008. Parasitology 136, 1719-1730.

Fleming, F.M., Brooker, S., Geiger, S.M., Caldas, I.R., Correa-Oliveira, R., Hotez, P.J., Bethony, J.M. (2006). Synergistic associations between hookworm and other helminth species in a rural community in Brazil. Trop. Med. Int. Health 11, 56-64. 
Forrester, J.E., Scott, M.E., Bundy, D.A., Golden, M.H. (1988). Clustering of Ascaris lumbricoides and Trichuris trichiura infections within households. Trans. R. Soc. Trop. Med. Hyg. 82, 282-288.

Forrester, J.E., Scott, M.E., Bundy, D.A.P., Golden, M.H.N. (1990). Predisposition of individuals and families in Mexico to heavy infection with Ascaris lumbricoides and Trichuris trichiura. Trans. R. Soc. Trop. Med. Hyg. 84, 272-276.

Garba, A., Touré, S., Dembelé, R., Boisier, P., Tohon, Z., Bosqué-Oliva, E., Koukounari, A., Fenwick, A. (2009). Present and future schistosomiasis control activities with support from the Schistosomiasis Control Initiative in West Africa. Parasitology 136, 1731-1737.

Gilles, H. (1996). Soil-transmitted helminths (geohelminths). In: Tropical Diseases. Cook, G. (Ed.), Manson's. W.B. Saunders, London, United Kingdom, pp. 1369-1412.

Hall, A. (1981). Quantitative variability of nematode egg counts in faeces: a study among rural Kenyans. Trans. R. Soc. Trop. Med. Hyg. 75, 682-687.

Horton, J., Witt, C., Ottensen, E.A., Lazdins, J.K., Addiss, D.G., Awadzi, K., Beach, M.J., Belizario, V.Y., Dunyo, S.K., Espinel, M., Gyapong, J.O., Hossain, M., Ismail, M.M., Jayakody, R.L., Lammie, P.J., Makunde, W., Richard-Lenoble, D., Selve, B., Shenoy, R.K., Simonsen, P.E., Wamae, C.N., Weerasooriya, M.V. (2000). An analysis of the safety of single dose, two drug regimens used in programmes to eliminate lymphatic filariasis. Parasitology 121, S147-S160.

Hotez, P.J., Brindley, P.J., Bethony, J.M., King, C.H., Pearce, E.J., Jacobson, J. (2008). Helminth infections: the great neglected tropical diseases. The Journal of Clinical Investigation 118, 1311-1321.

Hotez, P.J., Bundy, D.A.P., Beegle, K., Brooker, S., de Silva, N., Montresor, A., Engels, D., Drake, L., Chitsulo, L., Michaud, C., Bethony, J.M., Oliveira, R., Xiao, S.H., Fenwick, A., Savioli, L. (2006). Helminth infections: soil-transmitted helminth infections and schistosomiasis. In: Disease Control Pririoties in Developing Countries, $2^{\text {nd }}$ Edition. D. Jamison, M. Claeson, J. Breman and A. Meacham, eds. New York: Oxford University Press.

Hotez, P.J., Fenwick, A., Savioli, L., Molyneux, D.H. (2009). Rescuing the bottom billion through control of neglected tropical diseases. Lancet 373, 1570-1575.

Hotez, P.J., Molyneux, D.H., Fenwick, A., Kumaresan, J., Ehrlich Sachs, S., Sachs, J.D., Savioli, L. (2007). Control of neglected tropical diseases. N. Engl. J. Med. 357, 10181027.

Hotez, P.J., Engels, D., Fenwick, A., Savioli, L. (2010). Africa is desperate for praziquantel. Lancet, 376: 496-498.

Kabatereine, N.B., Brooker, S., Koukounari, A., Kazibwe, F., Tukahebwa, E.M., Fleming, F.M., Zhang, Y.B., Webster, J.P., Stothard, J.R., Fenwick, A. (2007). Impact of a national helminth control programme on infection and morbidity in Ugandan schoolchildren. Bull. World Health Organ. 85, 91-99.

Katz, N., Chaves, A., Pelligrino, J. (1972). A simple device for quantitative stool thicksmear technique in schistosomiasis mansoni. Rev. Inst. Med. Trop. Sao Paulo 14, 397-400.

Knopp, S., Mgeni, A.F., Khamis, I.S., Steinmann, P., Stothard, J.R., Rollinson, D., Marti, H., Utzinger, J. (2008). Diagnosis of soil-transmitted helminths in the era of preventive chemotherapy: effect of multiple stool sampling and use of different diagnostic techniques. PLoS Negl. Trop. Dis. 2, e331. 
Knopp, S., Rinaldi, L., Khamis, I.S., Stothard, J.R., Rollinson, D., Maurelli, M.P., Steinmann, P., Marti, H., Cringoli, G., Utzinger, J. (2009). A single FLOTAC is more sensitive than triplicate Kato-Katz for the diagnosis of low-intensity soil-transmitted helminth infections. Trans. R. Soc. Trop. Med. Hyg. 103, 347-354.

Levecke, B., De Wilde, N., Vandenhoute, E., Vercruysse, J. (2009). Field validity and feasibility of four techniques for the detection of Trichuris in Simians: a model for monitoring drug efficacy in public health? PLoS Negl. Trop. Dis. 3, e366.

Lin D.D., Liu J.X., Liu Y.M., Hu F., Zhang Y.Y., et al. (2008). Routine Kato-Katz technique underestimates the prevalence of Schistosoma japonicum: a case study in an endemic area of the People's Republic of China. Parasit. Int. 57, 281-286.

Linehan, M., Hanson, C., Weaver, A., Baker, M., Kabore, A., Zoerhoff, K.L.; Sankara, D., Torres, S., Ottensen, E. (2011). Integrated implementation of programs targeting naglected tropical diseases through preventive chemotherapy: proving the feasibility at national scale. American Journal of Tropical Medicine and Hygiene, 84, 1: $5-14$.

Miguel, E., Kremer, M. (2004). Worms: Identifying impacts on education and health in the presence of treatment externalities. Econometrica 72, 159-217.

Minsante (2005). Programme National de Lutte contre la Schistosomiase et les Helminthiases Intestinales: Plan stratégique 2005-2010. Ministère de la Santé Publique, Cameroun.

Mohammed, K.A., Haji, H.J., Gabrielli, A.F., Mubila, L., Biswas, G., Chitsulo, L., Bradley, M.H., Engels, D., Savioli, L., Molyneux, D.H. (2008). Triple co-administration of ivermectin, albendazole and praziquantel in Zanzibar: a safety study. PLoS Negl. Trop. Dis. 2 (1), e171.

Molyneux, D. H., Hotez, P., Fenwick, A. (2005). Rapid impact interventions: how a policy of integrated control for Africa's neglected tropical diseases could benefit the poor. PLoS Medicine 2, 1064-1070.

Molyneux, D.H., Hotez, P.J., Fenwick, A. (2005). Rapid impact interventions: how a policy of integrated control for Africa's neglected tropical diseases could benefit the poor. PLoS Medecine 2, 1064-1070.

Montresor, A., Crompton, D.W.T., Hall, A., Bundy, D.A.P., Savioli, L. (1998). Guidelines for the Evaluation of Soil-transmitted Helminthiasis and Schistosomiasis at Community Level: A Guide for Managers of Control Programmes. World Health Organization, Geneva.

Odogwu, S.E., Ramamurthy, N.K., Kabatereine, N.B., Kazibwe, F., Tukahebwa, E.,Webster, J.P., Fenwick, A., Stothard, J.R. (2006). Intestinal schistosomiasis in infants (3 years of age) along the Ugandan shoreline of Lake Victoria. Ann. Trop. Med. Parasitol. 100, 315-326.

Olds, G.R., King, C., Hewlett, J., Olveda, R., Wu, G., Ouma, J., Peters, P., McGarvey, S., Odhiambo, O., Koech, D., Liu, C.Y., Aligui, G., Gachihi, G., Kombe, Y., Parraga, I., Ramirez, B., Whalen, C., Horton, R.J., Reeve, P. (1999). Double blind, placebocontrolled study of concurrent administration of albendazole and praziquantel in schoolchildren with schistosomiasis and geohelminths. J. Infect. Dis. 179, 996-1003.

Ratard, R. C., Kouemeni, L. E., Ekani Bessala, M. M., Ndamkou, C. N., Greer, G. J., Spilsburg, J., Cline, B. L. (1990). Human schistosomiasis in Cameroon. I. 
Distribution of schistosomiasis. American Journal of Tropical Medicine and Hygiene 42, 561-572.

Ratard, R. C., Kouemeni, L. E., Ekani Bessala, M. M., Ndamkou, C. N., Sama, M. T., Cline, B. L. (1991). Ascariasis and trichuriasis in Cameroon. Transactions of the Royal Society of Tropical Medicine and Hygiene 85, 84-88.

Savioli, L., Albonico, M., Engels, D., Montresor, A. (2004). Progress in the prevention and control of schistosomiasis and soil-transmitted helminthiasis. Parasitol. Int. 53, 103113.

Savioli, L., Gabrielli, A.F., Montresor, A., Chitsulo, L., Engels, D. (2009). Schistosomiasis control in Africa: 8 years after World Health Assembly Resolution 54.19. Parasitology 136, 1677-1681.

Sékétéli, A., Adeoye, G., Eyamba, A., Nnoruka, E., Drameh, P., Amazigo, U.V., Noma, M., Agboton, F., Aholou, Y., Kale, O.O., Dadzie, K.Y. (2002). The achievements and challenges of the African Programme for Onchocerciasis Control (APOC). Ann. Trop. Med. Parasitol. 96 (Suppl. 1), S15-S28.

Shane H.L.L., Verani J.R., Abudho B., Montgomery S.P., Blackstock A.J., Mwinzi P.N.M., Butler S.E., Karanja D.M.S., Secor W.E. (2011). Evaluation of urine CCA assays for detection of Schistosoma mansoni infection in Western Kenya. PLoS Negl. Trop. Dis. 5(1): e951. doi:10.1371/journal.pntd.0000951.

Sousa-Figueiredo, J.C., Basanez, M.G., Mgeni, A.F., Khamis, I.S., Rollinson, D., Stothard, J.R. (2008). A parasitological survey, in rural Zanzibar, of pre-school children and their mothers for urinary schistosomiasis, soil-transmitted helminthiases and malaria, with observations on the prevalence of anaemia. Ann. Trop. Med. Parasitol. 102, 679_ 692.

Steinmann, P., Du, Z.W., Wang, L.B., Wang, X.Z., Jiang, J.Y., Li, L.H., Marti, H., Zhou, X.N., Utzinger, J. (2008). Extensive multiparasitism in a village of Yunnan Province, People's Republic of China, revealed by a suite of diagnostic methods. Am. J. Trop. Med. Hyg. 78, 760-769.

Steinmann, P., Keiser, J., Bos, R., Tanner, M., Utzinger, J. (2006). Schistosomiasis and water resources development: systematic review, meta-analysis, and estimates of people at risk. Lancet Infectious Diseases 6, 411-425.

Stephenson, L.S., Latham, M.C., Ottesen, E.A. (2000). Malnutrition and Parasitic Helminth Infections. Parasitology 121 (Suppl.), S23-28.

Stothard, J.R., Imison, E., French, M.D., Sousa-Figueiredo, J.C., Khamis, I.S., Rollinson, D. (2008). Soil-transmitted helminthiasis among mothers and their pre-school children on unguja island, zanzibar with emphasis upon ascariasis. Parasitology 135, 14471455.

Stothard J.R., Sousa-Figuereido J.C., Betson M., Adriko M., Arinaitwe M., et al. (2011). Schistosoma mansoni infections in young children: when are schistosome antigens in urine, eggs in stool and antibodies to eggs first detectable? PLoS Negl. Trop. Dis. 5(1): e938. doi:10.1371/journal.pntd.0000938

Tarafder, M.R., Carabin, H., Joseph, L., Balalong Jr., E., Olveda, R., McGarvey, S.T. (2009). Estimating the sensitivity and specificity of Kato-Katz stool examination technique for detection of hookworms, Ascaris lumbricoides and Trichuris trichiura infections in humans in the absence of a 'gold standard'. Int. J. Parasitol., doi:10.1016/j.ijpara.2009.09.003. 
Tchuem Tchuenté, L.A. (2011). Control of soil-transmitted helminths in sub-Saharan Africa: Diagnosis, drug efficacy concerns and challenges. Acta Tropica 120S, S4- S11.

Tchuem Tchuenté, L.A., N'Goran, E.K. (2009). Schistosomiasis and soil-transmitted helminthiasis control in Cameroon and Côte d'Ivoire: implementing control on a limited budget. Parasitology 136, 1736-1745.

Tchuem Tchuenté, L.A., Behnke, J.M., Gilbert, F., Southgate, V.R., Vercruysse, J. (2003). Polyparasitism with Schistosoma haematobium and soil-transmitted helminth infections among school children in Loum, Cameroon. Tropical Medicine and International Health 8, 975-986.

Tchuem Tchuenté, L.A., Kamwa Ngassam, R.I., Sumo, L., Ngassam, P., Dongmo Noumedem, C., Luogbou, D.G.O., Dankoni, E., Kenfack, C.M., Feussom Gipwe, N., Akame, J., Tarini, A., Zhang, Y., Angwafo III, F.F. (2012); Mapping of schistosomiasis and soil-transmitted helminthiasis in the regions of Centre, East and West Cameroon. PLoS Negl. Trop. Dis. (in press).

Tchuem Tchuenté L.A., Kueté Fouodo C.J., Kamwa Ngassam R.I., Sumo L., Dongmo Noumedem C., Kenfack C.M., Feussom Gipwe N., Dankoni Nana E., Stothard J.R., Rollinson D. (2012). Evaluation of circulating cathodic antigen (CCA) urine-tests for diagnosis of Schistosoma mansoni infection in Cameroon. PLoS Negl. Trop. Dis. (in press).

Utzinger, J., Rinaldi, L., Lohourignon, L.K., Rohner, F., Zimmermann, M.B., Tschannen, A.B., N'Goran, E.K., Cringoli, G. (2008). FLOTAC: a new sensitive technique for the diagnosis of hookworm infections in humans. Trans. R. Soc. Trop. Med. Hyg. 102, 84-90.

World Health Organization (2002). Prevention and control of schistosomiasis and soiltransmitted helminthiasis. Report of a WHO Expert Committee. WHO Technical Report Series No. 912. World Health Organization, Geneva.

World Health Organization (2006). Preventive chemotherapy in human helminthiasis: coordinated use of anthelminthic drugs in control interventions : a manual for health professionals and programme managers. World Health Organization Press, Geneva.

World Health Organization (2010). Soil-transmitted helminthiasis: number of children treated 2007-2008: update on the 2010 global target. Weekly Epidemiological Record 16, 85: 141-148.

World Health Organization (2011). Schistosomiasis: number of people treated, 2009. Weekly Epidemiological Record 9, 86: 73-80.

World Health Organization (2012). Schistosomiasis: population requiring preventive chemotherapy and number of people treated in 2010. Weekly Epidemiological Record 4, 87: 37-44.

World Health Organization (1991). Basic Laboratory Methods in Medical Parasitology. World Health Organization, Geneva. 


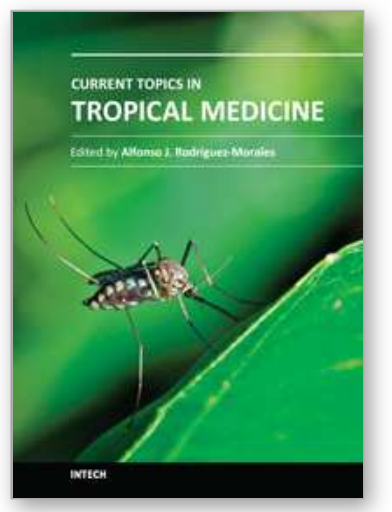

\author{
Current Topics in Tropical Medicine \\ Edited by Dr. Alfonso Rodriguez-Morales
}

ISBN 978-953-51-0274-8

Hard cover, 564 pages

Publisher InTech

Published online 16, March, 2012

Published in print edition March, 2012

Tropical Medicine has emerged and remained as an important discipline for the study of diseases endemic in the tropic, particularly those of infectious etiology. Emergence and reemergence of many tropical pathologies have recently aroused the interest of many fields of the study of tropical medicine, even including new infectious agents. Then evidence-based information in the field and regular updates are necessary. Current Topics in Tropical Medicine presents an updated information on multiple diseases and conditions of interest in the field. It Includes pathologies caused by bacteria, viruses and parasites, protozoans and helminths, as well as tropical non-infectious conditions. Many of them are considering not only epidemiological aspects, but also diagnostic, therapeutical, preventive, social, genetic, bioinformatic and molecular ones. With participation of authors from various countries, many from proper endemic areas, this book has a wide geographical perspective. Finally, all of these characteristics, make an excellent update on many aspects of tropical medicine in the world.

\title{
How to reference
}

In order to correctly reference this scholarly work, feel free to copy and paste the following:

Louis-Albert Tchuem Tchuenté (2012). Control of Schistosomiasis and Soil-Transmitted Helminthiasis in SubSaharan Africa: Challenges and Prospects, Current Topics in Tropical Medicine, Dr. Alfonso RodriguezMorales (Ed.), ISBN: 978-953-51-0274-8, InTech, Available from: http://www.intechopen.com/books/currenttopics-in-tropical-medicine/control-of-schistosomiasis-and-soil-transmitted-helminths-in-sub-saharan-africachallenges-and-prosp

\section{INTECH}

open science | open minds

\section{InTech Europe}

University Campus STeP Ri

Slavka Krautzeka 83/A

51000 Rijeka, Croatia

Phone: +385 (51) 770447

Fax: +385 (51) 686166

www.intechopen.com

\section{InTech China}

Unit 405, Office Block, Hotel Equatorial Shanghai

No.65, Yan An Road (West), Shanghai, 200040, China 中国上海市延安西路65号上海国际贵都大饭店办公楼405单元

Phone: +86-21-62489820

Fax: +86-21-62489821 
(C) 2012 The Author(s). Licensee IntechOpen. This is an open access article distributed under the terms of the Creative Commons Attribution 3.0 License, which permits unrestricted use, distribution, and reproduction in any medium, provided the original work is properly cited. 